\title{
Single-Item Measures for Detecting Sleep Problems in United States Military Veterans
}

\author{
Jaime M. Hughes, PhD, MPH, MSW' , Christi S. Ulmer, $P h D^{1,2}$, \\ Jennifer M. Gierisch, PhD, MPH ${ }^{1,3}$ Mid-Atlantic VA MIRECC Workgroup ${ }^{4}$, and Matthew O. Howard, \\ $P h D, M A, M S W^{5}$
}

'Center for Health Services Research in Primary Care, Durham VA Medical Center, Durham, NC, USA; ${ }^{2}$ Department of Psychiatry and Behavioral Sciences, Duke University Medical School, Durham, NC, USA; ' ${ }^{2}$ Division of General Internal Medicine, Duke University Medical School, Durham, NC, USA; ${ }^{4}$ Mental Illness Research, Education, and Clinical Center, Durham VA Medical Center, Durham, NC, USA; ${ }^{5}$ School of Social Work, University of North Carolina at Chapel Hill, Chapel Hill, NC, USA.

BACKGROUND: As many as two-thirds of post-9/11 military veterans complain of sleep problems, including insomnia-like symptoms. Left untreated, chronic sleep problems increase the risk for a range of negative outcomes, including incident mental health disorders. However, sleep problems remain overlooked in primary care settings. To date, no brief sleep screeners have been developed or validated. Items assessing insomnia and poor sleep are often embedded into commonly used psychological assessments, and may serve as a viable first step in screening.

OBJECTIVE: The objective of this study was to examine the utility of three single items (i.e., trouble falling asleep, awakening in the early morning, and sleep that is restless or disturbed) embedded into the Symptom Checklist-90Revised (SCL) for identifying two outcomes of interest, poor sleep and probable insomnia.

DESIGN: Data were drawn from the cross-sectional PostDeployment Mental Health Study, hosted by the MidAtlantic VA Mental Illness Research, Education, and Clinical Center. Item performance was evaluated using sensitivity, specificity, and predictive value calculations, along with receiver operating characteristic (ROC) curves.

PARTICIPANTS: Post-9/11 U.S. military veterans with one or more overseas deployments and with no current DSM Axis I mental health disorder $(N=1118)$.

MAIN MEASURES: An in-person health and sleep questionnaire, including the Pittsburgh Sleep Quality Index (PSQI) and the Symptom Checklist (SCL).

KEY RESULTS: Using an item response of 1, all three items demonstrated moderate sensitivity (0.70-0.78) and acceptable rates of false positives and false negatives (0.23-0.48 and 0.11-0.42, respectively) in predicting both outcomes, poor sleep and probable insomnia.

CONCLUSIONS: Our initial findings suggest that existing items in the SCL may serve as a first step in screening for sleep problems. Early detection and treatment of sleep problems might prevent or ameliorate several negative outcomes, including incident mental health disorders.

KEY WORDS: screening; primary care; prevention; mental health; veterans.

Received March 8, 2017

Revised July 5, 2017

Accepted November 22, 2017

Published online January 23, 2018
J Gen Intern Med 33(5):698-704

DOI: $10.1007 / \mathrm{s} 11606-017-4250-4$

(c) Society of General Internal Medicine (outside the USA) 2017

\section{INTRODUCTION}

Sleep problems are a common complaint among United States military veterans. ${ }^{1,2}$ Insomnia symptoms, including trouble falling or staying asleep, waking up earlier than desired, and excessive daytime fatigue and impairment as a result of restless or disturbed nighttime sleep, are particularly common. ${ }^{3,4}$ Sleep problems contribute to impaired performance, ${ }^{5}$ reduced quality of life, ${ }^{6}$ and increased healthcare utilization. ${ }^{7}$ Chronic insomnia has been linked to increased risk for incident mental health disorders ${ }^{8-11}$ and suicidal ideation and attempts. ${ }^{12}$ Early screening and treatment of sleep problems might prevent or ameliorate negative outcomes.

Full-length, multi-item sleep questionnaires, including the Pittsburgh Sleep Quality Index ${ }^{13}$ and Insomnia Severity Index, ${ }^{14}$ are considered feasible, reliable assessment tools. ${ }^{15}$ However, many primary care providers are unfamiliar with how to deliver and score sleep questionnaires. Moreover, the limited time available for most primary care encounters may prevent providers from completing full-length sleep questionnaires. Brief measures composed of two to four items are frequently used to assess symptoms of other common conditions, including depression (e.g., Patient Health Questionnaire-2) ${ }^{16}$ and post-traumatic stress disorder (Primary Care Post Traumatic Stress Disorder Screen). ${ }^{17}$ However, no brief sleep measures have been developed or validated to date. In the absence of full-length sleep questionnaires or validated brief measures, existing single sleep items may function as a first-line assessment tool.

Items assessing insomnia symptoms, such as difficulty falling or staying asleep or sleep that is restless or disturbed, are embedded in commonly used psychological assessments, including the Symptom Checklist, ${ }^{18}$ Patient Health Questionnaire- $9,{ }^{19}$ and PTSD Checklist. ${ }^{20}$ To our knowledge, the utility of single-item screeners in identifying veterans with sleep problems has been examined in only one other study. ${ }^{21}$ 
However, this study evaluated an item assessing both insomnia and hypersomnia using participants from a larger research study focused on alcohol use. The current study adds to the literature by evaluating the sensitivity and specificity of three sleep items included in the Symptom Checklist-90-Revised in relation to two outcomes of interest, the Pittsburgh Sleep Quality Index ${ }^{13}$ and a DSM-5-based probable insomnia diagnosis, among a general population of post-9/11 veterans.

\section{METHODS}

\section{Procedures and Participants}

Data presented herein were collected as a part of the PostDeployment Mental Health Study sponsored by the Veterans Affairs Mid-Atlantic Mental Illness, Research, Education, and Clinical Center (MIRECC). Participants were recruited via flyers, mailings, and provider referrals for a study focusing on post-deployment health at four medical centers within the Mid-Atlantic region (Durham and Salisbury, NC; Hampton and Richmond, VA). Institutional review board approval was obtained at each of the four participating sites.

To participate in the study, individuals had to have served in the U.S. military since September 11, 2001, speak English, be able to travel to one of the study enrollment sites, and demonstrate comprehension of the informed consent process. After providing informed consent, all study participants completed a daylong assessment battery, including an in-person structured diagnostic interview. All participants were compensated \$175 for their time and participation. The final sample included 1118 participants who had one or more overseas deployments, were free from a past-month DSM-IV Axis I mental health disorder, and had complete data on the Pittsburgh Sleep Quality Index (PSQI).

\section{Measures}

Demographics and Health Questionnaires. All participants reported basic demographic characteristics including age, race, gender, marital status, total years of education, current working status, and number of military tours served.

Overall health status was assessed using the National Vietnam Veterans Readjustment Survey Medical Questionnaire, ${ }^{22}$ which assesses the presence or absence of 37 chronic physical health conditions over the prior year and over an individual's lifetime. A higher number of chronic conditions indicates worse overall health.

The Symptom Checklist-90-Revised (hereinafter SCL) ${ }^{23}$ is a 90-item self-report questionnaire frequently used in medical and research settings to assess global psychological distress. Respondents indicate the degree of distress experienced for each of 90 symptoms over the past 7 days. Response options fall along a five-point Likert scale and include the following: $0=$ not at all, $1=$ a little bit, $2=$ moderately, $3=$ quite a bit, or $4=$ extremely distressing. The SCL includes three sleep items that were the focus of our analyses: trouble falling asleep (item 44), awakening in the early morning (item 64), and sleep that is restless or disturbed (item 66). These items are related to different aspects of insomnia, including difficulty with sleep initiation (item 44), sleep maintenance (item 64), and non-restorative or unrefreshing sleep (item 66). Of note, item 66 may capture symptoms due to other disorders, including sleep apnea.

Clinical Markers of Sleep Problems. For this study, two outcomes were used to categorize individuals as having clinically significant sleep problems. The Pittsburgh Sleep Quality Index (PSQI) ${ }^{13}$ is a 19 -item self-report questionnaire assessing sleep patterns, disturbances, and consequences over the prior month. Total scores range from 0 to 21, with scores greater than 5 indicative of clinically significant poor sleep. The PSQI has demonstrated strong reliability in a variety of settings ${ }^{24}$ and is considered a gold-standard self-reported assessment of sleep quality. ${ }^{15}$ The total score from the PSQI was used to differentiate individuals with and without clinically significant poor sleep. Given the multidimensional nature of the PSQI, the total score may reflect poor sleep that results from a variety of causes, including insomnia symptoms, sleep apnea, chronic pain, or bad dreams.

Probable insomnia disorder was approximated based on how items from self-reported measures mapped onto the DSM-5 criteria. ${ }^{25}$ Participants were identified as having probable insomnia if all of the following criteria were endorsed: complaint of difficulty falling or staying asleep or waking up too early (criterion A); daytime fatigue or disturbance as a result of poor sleep (criterion B); and symptoms occurring at least three times per week (criterion C). Refer to Table 1 for a more detailed description of our probable insomnia disorder approximation. Sleep problems were drawn from the PSQI, Davidson Trauma Scale, ${ }^{26}$ and Beck Depression Inventory. ${ }^{27}$

\section{Analyses}

Data were analyzed using SPSS 21.0 software. ${ }^{28}$ Prior to evaluating the performance of individual items, descriptive statistics were calculated for all demographic variables and sleep characteristics. The performance of each of the three sleep items (trouble falling asleep, awakening in the early morning, sleep that is restless or disturbed) was evaluated in relation to two outcome measures, PSQI-defined poor sleep and an approximated DSM-5-defined insomnia disorder diagnosis.

The following calculations were obtained at each response score for all three SCL "screening" items in predicting our two reference outcomes: sensitivity (proportion of participants correctly identified by an SCL item as having sleep problems; true positives/[true positives + false negatives]); specificity (proportion of participants correctly identified by an SCL item as not having sleep problems; true negatives/[true negatives + false positives]); efficiency (percentage of SCL screeners 
Table 1 Criteria Used to Approximate DSM-5 Probable Insomnia among U.S. Military Veterans

\begin{tabular}{|c|c|c|}
\hline & DSM-5 criterion & $\begin{array}{l}\text { Criterion met if one or } \\
\text { more of the following } \\
\text { were endorsed }\end{array}$ \\
\hline $\begin{array}{l}\text { Criterion } \\
\text { A }\end{array}$ & $\begin{array}{l}\text { Dissatisfaction with sleep } \\
\text { quantity or quality, with one } \\
\text { or more symptoms: } \\
\text { difficulty initiating sleep, } \\
\text { difficulty maintaining sleep, } \\
\text { or early morning awakening }\end{array}$ & $\begin{array}{l}\text { Cannot get to sleep within } \\
30 \text { min (PSQI, item 5_1) } \\
\text { OR } \\
\text { Wake up in the middle of } \\
\text { the night or early morning } \\
\text { (PSQI, item } 5 \text { 2) OR } \\
\text { Difficulty falling or } \\
\text { staying asleep (DTS: item } \\
12 \text { 1) }\end{array}$ \\
\hline $\begin{array}{l}\text { Criterion } \\
\text { B }\end{array}$ & $\begin{array}{l}\text { Sleep disturbance causes } \\
\text { significant distress or } \\
\text { impairment in social, } \\
\text { occupational, educational, } \\
\text { academic, behavioral, or } \\
\text { other impaired areas of } \\
\text { functioning }\end{array}$ & $\begin{array}{l}\text { Trouble staying awake } \\
\text { while driving, eating } \\
\text { meals, or engaging in } \\
\text { social activities (PSQI, } \\
\text { item 8, response: three or } \\
\text { more times/week) OR } \\
\text { Problem keeping up } \\
\text { enough enthusiasm to get } \\
\text { things done (PSQI, item } \\
9 \text {, response: somewhat of } \\
\text { a problem or a very big } \\
\text { problem) OR } \\
\text { Too tired or fatigued to do } \\
\text { a lot of the things I used } \\
\text { to do (BDI, item 20) OR } \\
\text { Too tired or fatigued to do } \\
\text { most of the things I used } \\
\text { to do (BDI, item 20) }\end{array}$ \\
\hline $\begin{array}{l}\text { Criterion } \\
\mathrm{C}\end{array}$ & $\begin{array}{l}\text { Three times/week for at least } \\
3 \text { months despite an ade- } \\
\text { quate opportunity for sleep }\end{array}$ & $\begin{array}{l}\text { Frequency evaluated by } \\
\text { one or more of the } \\
\text { complaints listed under } \\
\text { criterion A endorsed as } \\
\text { occurring three or more } \\
\text { times per week } \\
\text { Cannot confirm duration } \\
\text { of symptoms at this time }\end{array}$ \\
\hline $\begin{array}{l}\text { Criterion } \\
\text { D }\end{array}$ & $\begin{array}{l}\text { Does not co-occur with an- } \\
\text { other sleep disorder }\end{array}$ & $\begin{array}{l}\text { Cannot confirm at this } \\
\text { time; no sleep history } \\
\text { available }\end{array}$ \\
\hline $\begin{array}{l}\text { Criterion } \\
\mathrm{E}\end{array}$ & $\begin{array}{l}\text { Insomnia complaints are not } \\
\text { explained by coexisting } \\
\text { mental disorders or medical } \\
\text { conditions }\end{array}$ & $\begin{array}{l}\text { Cannot confirm at this } \\
\text { time; no sleep history or } \\
\text { medical history available }\end{array}$ \\
\hline
\end{tabular}

DTS Davidson Trauma Scale, BDI Beck Depression Inventory

that produced correct classifications relative to total number of tests; [true positives + true negatives]/[true positives + false positives + true negatives + false negatives]); false-positive rate (percentage of SCL screeners that produced a false result when sleep problems were not present; 1-specificity); and falsenegative rate (percentage of SCL screening tests that failed to produce positive results when sleep problems were present; 1 sensitivity).

Receiver operating characteristic (ROC) curves were constructed for each of the three sleep items based on our two reference outcomes of interest. ROC curves examine sensitivity, specificity, and the area under the curve (AUC), a measure representing the probability that the screening test result from any randomly chosen positive case will exceed the result for a randomly chosen negative case. An area of 1.0 represents a perfectly accurate test, while an area of 0.50 represents a screening test that is no more accurate or efficient than chance alone. ${ }^{29-31}$

\section{RESULTS}

Most of the 1118 veterans who participated in this study were men $(80.1 \%, n=894)$. The sample had roughly equal proportions of white $(52 \%, N=565)$ and African-American $(44 \%$, $N=495)$ participants. The average age of participants was 38.0 years $(\mathrm{SD}=10.4)$. Participants reported 1.74 average tours of duty (overseas deployment; $\mathrm{SD}=1.4$ ). Additional demographic and health characteristics are shown in Table 2.

Sleep problems were common in our sample. Approximately $60 \%$ of participants met clinical criteria for poor sleep, as indicated by a score greater than 5 on the PSQI ${ }^{13}(58.5 \%, N=$ 654 , average PSQI total score $=7.2$ ). Just under $20 \%$ of the sample $(N=202)$ met criteria for DSM-5 probable insomnia disorder based on approximated diagnostic criteria. Thirty percent of participants who met criteria for poor sleep also met criteria for probable insomnia disorder. The discrepancy between the two outcomes may be explained by sleep disorders other than insomnia (i.e., obstructive sleep apnea, restless leg syndrome, nightmares) that contribute to a higher rate of poor sleepers.

First, the performance of the three SCL sleep items in predicting overall poor sleep was examined. Results for sensitivity, specificity, efficiency, and false-positive and false-negative fractions for each of the possible response options on the three SCL items are displayed in Table 3. Sensitivity and specificity were optimized at the lowest response option of 0 . A response option of 1 (a little distressing) resulted in high sensitivity (range: 0.58-0.74) but resulted in a false-positive fraction of 0.23-0.30. A response option of 2 (moderately distressing) resulted in lower sensitivity (0.33-0.47), higher specificity $(0.90-0.97)$, and a false-positive fraction of $0.05-0.10$.

Receiver operating characteristic curves were constructed to evaluate the accuracy of each of the three SCL items for discriminating between "poor sleepers" and "good sleepers,"

Table 2 Participant Demographics and Sleep Characteristics $(N=$ 1118)

\begin{tabular}{ll}
\hline \hline Demographic Characteristics & Mean (SD) \\
\hline Age & $38.0(10.4)$ \\
Gender, male, $n(\%)$ & $913(82)$ \\
Race, $n(\%)$ & $565(51)$ \\
White, non-Hispanic & $495(44)$ \\
Black, non-Hispanic & $47(4)$ \\
Other & $13.7(3.8)$ \\
Education, total years & $635(57)$ \\
Married or living with a domestic partner, $n(\%)$ & $647(58)$ \\
Working full-time, $n(\%)$ & $1.74(1.4)$ \\
Number of tours served & $1.73(1.9)$ \\
Number of chronic health conditions in past year & $478(43)$ \\
Had one or more lifetime mental health disorders, $n$ & \\
(\%) & \\
Sleep Characteristics & $29.7(26.9)$ \\
Sleep onset latency (min) & $5.9(1.4)$ \\
Total sleep time (h) & $79.1 \%$ \\
Sleep efficiency percentage (total time asleep/total & $(19.7 \%)$ \\
time in bed) & $7.2(2.5)$ \\
Pittsburgh Sleep Quality Index, total score & $654(59)$ \\
Clinically significant poor sleep (PSQI $>5), n(\%)$ & $205(18)$ \\
Probable insomnia disorder, $n$ (\%) & \\
\hline
\end{tabular}


Table 3 Sensitivity and Specificity of SCL Single-Item Sleep Screeners in Predicting Overall Poor Sleep (PSQI >5) among U.S. Military Veterans

\begin{tabular}{|c|c|c|c|c|c|c|c|}
\hline Item & No. & $\begin{array}{l}\text { Response } \\
\text { option }\end{array}$ & Sensitivity & Specificity & Efficiency & $\begin{array}{l}\text { False-positive } \\
\text { rate }\end{array}$ & $\begin{array}{l}\text { False-negative } \\
\text { rate }\end{array}$ \\
\hline \multirow[t]{5}{*}{ SCL-44: Trouble falling asleep } & 537 & 0 & 1.00 & 0.00 & 0.59 & 1.00 & 0.00 \\
\hline & 259 & 1 & 0.73 & 0.78 & 0.75 & 0.23 & 0.27 \\
\hline & 123 & 2 & 0.45 & 0.95 & 0.66 & 0.05 & 0.55 \\
\hline & 116 & 3 & 0.29 & 0.98 & 0.58 & 0.02 & 0.71 \\
\hline & 83 & 4 & 0.13 & 0.99 & 0.49 & 0.00 & 0.87 \\
\hline SCL-64: Awakening in the early & 599 & 0 & 1.00 & 0.00 & 0.59 & 1.00 & 0.00 \\
\hline \multirow[t]{4}{*}{ morning } & 258 & 1 & 0.58 & 0.70 & 0.63 & 0.30 & 0.42 \\
\hline & 126 & 2 & 0.33 & 0.90 & 0.57 & 0.10 & 0.67 \\
\hline & 86 & 3 & 0.18 & 0.96 & 0.50 & 0.04 & 0.82 \\
\hline & 49 & 4 & 0.06 & 0.98 & 0.45 & 0.02 & 0.94 \\
\hline \multirow{5}{*}{$\begin{array}{l}\text { SCL-66: Sleep that is restless or } \\
\text { disturbed }\end{array}$} & 494 & 0 & 1.00 & 0.00 & 0.59 & 1.00 & 0.00 \\
\hline & 284 & 1 & 0.74 & 0.70 & 0.73 & 0.30 & 0.26 \\
\hline & 160 & 2 & 0.47 & 0.93 & 0.66 & 0.07 & 0.53 \\
\hline & 111 & 3 & 0.25 & 0.97 & 0.55 & 0.03 & 0.75 \\
\hline & 69 & 4 & 0.10 & 0.99 & 0.47 & 0.01 & 0.90 \\
\hline
\end{tabular}

and are displayed in Figure 1. The areas under the curve for each of the three items in predicting total PSQI option were as follows: item 44, trouble falling asleep: 0.79 ( $\mathrm{SE}=0.013$, $p<0.001$ ); item 64 , awakening in the early morning: 0.66 ( $\mathrm{SE}=0.016, p<0.001)$; and item 66 , sleep that is restless or disturbed: 0.77 ( $\mathrm{SE}=0.014, p<0.001)$.

Second, the performance of the three items in predicting probable insomnia disorder was examined. Results for sensitivity, specificity, efficiency, and false-positive and falsenegative fractions for each of the possible response options on the three SCL items are displayed in Table 4. Sensitivity and specificity were again optimized at the lowest response option of 0 . A response option of 1 resulted in high sensitivity (range: 0.81-0.89) but was associated with more false positives $(0.42-0.48)$. A response option of 2 resulted in moderate sensitivity (0.63-9.71) and specificity (0.79 for each item), while generating a false-positive fraction of roughly $20 \%$ (0.17-0.21).

ROC curves were constructed for each of the three SCL items discriminating between participants with and without probable insomnia disorder and are displayed in Figure 2. The areas under the curve for each of the three items in predicting probable insomnia disorder were as follows: item 44, trouble falling asleep: $0.76(\mathrm{SE}=0.020, p<0.001)$; item 64 , awakening in the early morning: 0.69 ( $\mathrm{SE}=0.022, p<0.001)$; and item 66 , sleep that is restless or disturbed, $0.80(\mathrm{SE}=0.017$, $p<0.001)$.

\section{DISCUSSION}

This study presents results suggesting that single-item sleep measures embedded in widely used psychological assessments may function as effective screeners for general sleep problems and probable insomnia disorder. Items evaluating trouble falling asleep, awakening in the early morning, and sleep that is restless or disturbed were moderately predictive of overall poor sleep, as measured by an elevated PSQI score, and probable insomnia disorder, as approximated based on DSM-5 diagnostic criteria. As indicated in Tables 3 and 4, a a

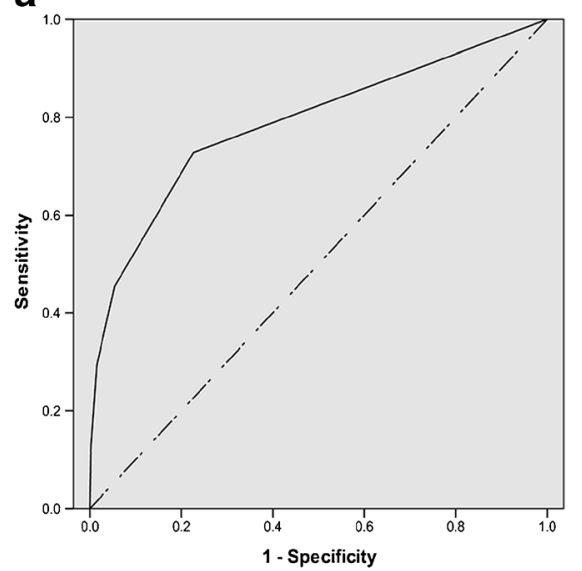

b

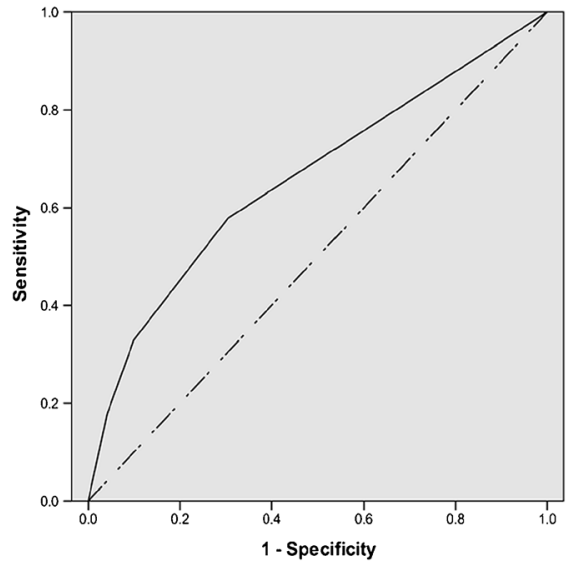

c

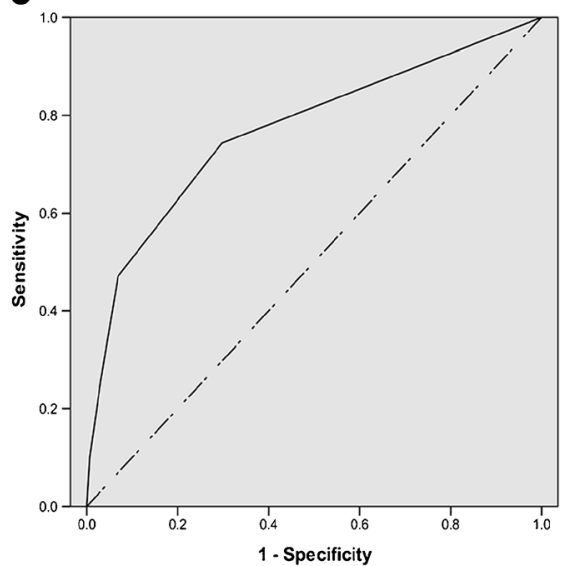

Figure 1 Receiver operating characteristic curves for single-item measures predicting overall poor sleep among veterans $(N=1118)$, a $S C L-44$ : Trouble falling asleep (AUC=0.79). b SCL-64: Awakening in the early morning (AUC=0.66). c SCL-66: Sleep that is restless or disturbed $(\mathrm{AUC}=\mathbf{0 . 7 7})$. 
Table 4 Sensitivity and Specificity of SCL Single-Item Sleep Screeners in Predicting Probable Insomnia Disorder among U.S. Military Veterans

\begin{tabular}{|c|c|c|c|c|c|c|c|}
\hline Item & No. & $\begin{array}{l}\text { Response } \\
\text { option }\end{array}$ & Sensitivity & Specificity & Efficiency & $\begin{array}{l}\text { False-positive } \\
\text { rate }\end{array}$ & $\begin{array}{l}\text { False-negative } \\
\text { rate }\end{array}$ \\
\hline \multirow[t]{5}{*}{ SCL-44: Trouble falling asleep } & 537 & 0 & 1.00 & 0.00 & 0.18 & 1.00 & 0.00 \\
\hline & 259 & 1 & 0.81 & 0.55 & 0.59 & 0.45 & 0.19 \\
\hline & 123 & 2 & 0.63 & 0.79 & 0.76 & 0.21 & 0.37 \\
\hline & 116 & 3 & 0.50 & 0.89 & 0.82 & 0.11 & 0.50 \\
\hline & 83 & 4 & 0.27 & 0.97 & 0.84 & 0.03 & 0.73 \\
\hline SCL-64: Awakening in the early & 599 & 0 & 1.00 & 0.00 & 0.18 & 1.00 & 0.00 \\
\hline \multirow{4}{*}{ morning } & 258 & 1 & 0.81 & 0.55 & 0.60 & 0.42 & 0.32 \\
\hline & 126 & 2 & 0.63 & 0.79 & 0.77 & 0.17 & 0.49 \\
\hline & 86 & 3 & 0.45 & 0.90 & 0.80 & 0.09 & 0.72 \\
\hline & 49 & 4 & 0.11 & 0.97 & 0.81 & 0.03 & 0.89 \\
\hline SCL-66: Sleep that is restless or & 494 & 0 & 1.00 & 0.00 & 0.18 & 1.00 & 0.00 \\
\hline \multirow[t]{4}{*}{ disturbed } & 284 & 1 & 0.89 & 0.52 & 0.59 & 0.48 & 0.11 \\
\hline & 160 & 2 & 0.71 & 0.79 & 0.77 & 0.21 & 0.29 \\
\hline & 111 & 3 & 0.49 & 0.90 & 0.82 & 0.10 & 0.55 \\
\hline & 69 & 4 & 0.20 & 0.97 & 0.83 & 0.03 & 0.80 \\
\hline
\end{tabular}

response option of 1 (indicating "a little" distress) on each of the three SCL screening items was able to detect poor sleep and probable insomnia disorder with fair sensitivity and a low false-positive rate. These findings may allow primary care providers not otherwise familiar with sleep questionnaires or formal diagnostic criteria to identify veterans with clinically significant sleep problems and refer them for more extensive evaluation.

In our evaluation of the three SCL sleep items, we prioritized sensitivity over specificity, for several reasons. First, as noted earlier, chronic sleep problems are associated with increased risk for poor physical and psychological health outcomes. Thus the detection and treatment of sleep problems early in their course is important. Second, additional in-depth screening for potential sleep disorders carries low burden and risk. Any subsequent screenings required can be administered using additional paper-based questionnaires or overnight home sleep monitoring. Third, the availability of safe and effective behavioral treatments is increasing within VHA settings, ${ }^{32-35}$ making treatment more accessible for veterans identified as having a sleep disorder.
In identifying and suggesting a response option indicative of poor sleep and probable insomnia disorder, we took several factors into account. Although sensitivity was highest for both outcomes at a response option of 1, this resulted in a falsepositive rate of $25 \%$ (poor sleep) to $45 \%$ (probable insomnia disorder). In predicting poor sleep, there was little change in specificity between response options of 2,3 , or 4 . In predicting probable insomnia disorder, efficiency was highest at response options of 2, 3, and 4, but sensitivity suffered. Although sensitivity and false-negative fractions were optimized using a response option of 4 , we caution against using such stringent cut points, since the goal for single-item sleep measures should be to identify a broad spectrum of veterans who are poor sleepers, including those whose sleep problems have not become severe or chronic.

Sensitivity and efficiency were generally higher in predicting probable insomnia disorder than poor sleep. This is unsurprising given that two of the three items evaluated (items 44 and 64) reflect common insomnia symptoms and should correlate well with probable insomnia disorder. On the other hand, the PSQI is a multidimensional instrument whose a

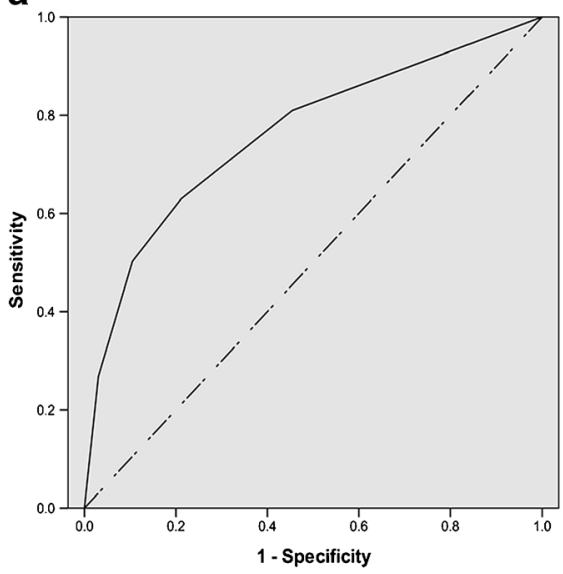

b

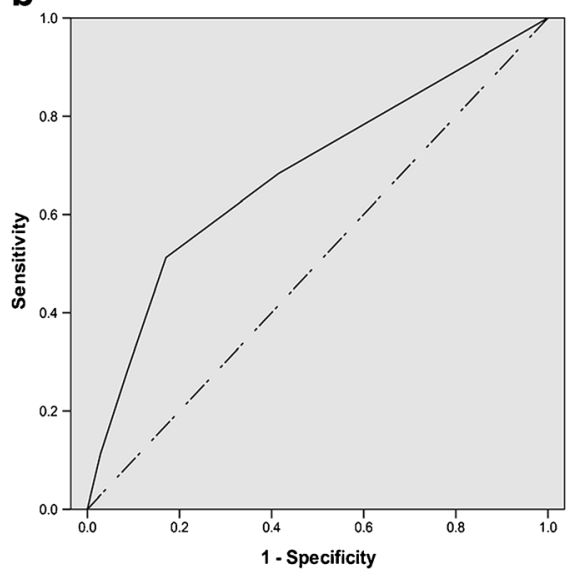

C

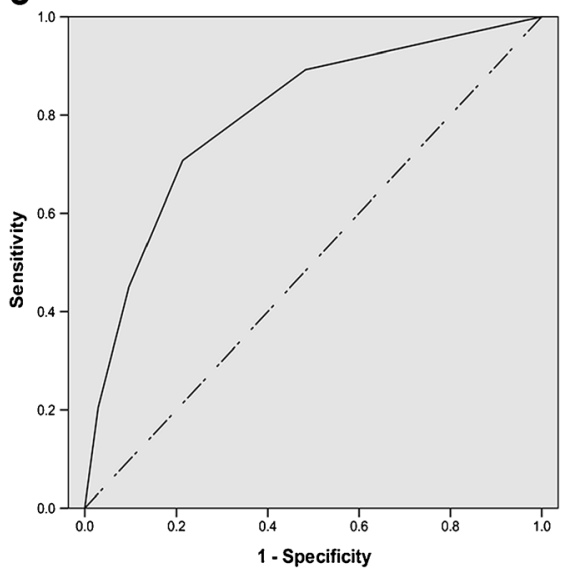

Figure 2 Receiver operating characteristic curves for single-item measures predicting probable insomnia disorder among veterans $(N=1118)$. a SCL-44: Trouble falling asleep (AUC=0.76). b SCL-64: Awakening in the early morning (AUC=0.69). c SCL-66: Sleep that is restless or disturbed $(\mathrm{AUC}=\mathbf{0 . 8 0})$. 
total score comprises seven component scores. As a result, overall poor sleep, as indicated by the PSQI, may reflect a combination of insomnia symptoms, short sleep duration, and accompanying daytime consequences of poor sleep. Despite these differences, two of the three items - trouble falling asleep and sleep that is restless or disturbed - demonstrated strong performance relative to both outcomes of interest. These are notable findings, as these items reflect common complaints related to the two most prevalent sleep disorders in veterans, insomnia disorder and sleep apnea.

While false positives are viewed negatively in many diagnostic tests, further evaluation for sleep problems following a positive screen carries low time and cost burdens for the patient. Although sleep problems may not be considered as serious as other medical conditions such as hypertension or cancer, the negative consequences of sleep problems can be severe. A false-negative test result runs the risk of a patient further dismissing subsyndromal sleep problems as unimportant, thereby increasing the risk of delaying further screening or treatment. A delay in treatment may be particularly consequential for serious conditions such as sleep apnea.

The greatest strength of our study is the opportunity to look at a sample of veterans who are known to be free of a current mental health disorder based on formal diagnostic evaluation. Given the known risks that chronic sleep problems pose for incident mental health disorders, our results may inform clinical screening and preventive practices in routine primary care. In light of the increasing prevalence of sleep apnea and insomnia in veterans, ${ }^{36}$ an additional strength of our study is in evaluating the performance of single items for predicting both overall poor sleep and unrecognized insomnia. The use of the PSQI rather than an insomnia-specific questionnaire such as the Insomnia Severity Index allowed us to capture sleep problems due to a number of different causes, including insomnia and sleep apnea. Prior research on single-item screeners has evaluated only insomnia symptoms, including trouble falling or staying asleep. ${ }^{21}$ An additional strength of our study is the inclusion and evaluation of a more global sleep item assessing sleep that is restless or disturbed (SCL item 66). This item potentially captures sleep problems that may stem from causes beyond insomnia, including pain or sleep apnea, and may be a strong candidate for a one- to two-item brief screener.

Despite numerous strengths, several limitations of this study should be noted. First, this study was not designed to collect an objective measure of sleep, such as outpatient wrist actigraphy or overnight polysomnography. Although readers may criticise our use of an approximated insomnia disorder diagnosis, there is currently no objective medical test for insomnia, and diagnosis is based purely on selfreport questionnaires and/or clinical interviews. Additionally, we were not able to determine the presence of other organic sleep disorders (e.g., restless leg syndrome, sleep apnea). Second, by limiting our analytic sample to veterans free of past-month mental health disorders at the time of study participation, we are not able to examine how veterans who report both sleep problems and mental health problems may evaluate the three items examined in this study. However, early detection of sleep problems in veterans without current symptoms of a mental health disorder is critical, given the established link between insomnia symptoms and heightened risk of subsequent mental health

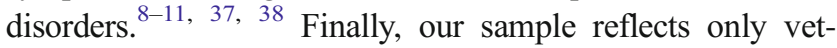
erans who elected to participate in research, thereby potentially limiting the generalizability of our findings both to the larger veteran population and non-veterans.

Although additional evaluation of the three SCL screening items should be conducted with a more diverse patient population, our results suggest that, particularly in the absence of validated brief screeners, existing items in the SCL may be a first step in identifying veterans with sleep problems. The three sleep items evaluated herein should not serve as a substitute for a full-length sleep questionnaire or formal evaluation by a sleep specialist. However, they provide an approach whereby primary care providers could play a role in addressing the growing problem of undetected sleep problems utilizing a single question to identify and triage veterans with suspected poor sleep or unrecognized insomnia disorder.

Acknowledgements: The Mid-Atlantic VA MIRECC Workgroup contributors for this paper include: Jean C. Beckham, PhD; Mira Brancu, PhD; Patrick S. Calhoun, PhD; Kathleen P. Decker, MD; Eric Dedert, PhD; Eric B. Elbogen, PhD; John A. Fairbank, PhD; Kimberly T. Green; Jason D. Kilts, PhD; Nathan Kimbrel, PhD; Angela Kirby, MS; Christine E. Marx, MD, MS; Scott D. Moore, $M D, P h D ;$ Rajendra A. Morey, MD, MS; Jennifer C. Naylor, PhD; Jennifer J. Runnals, PhD; Cindy Swinkels, PhD; Steven T. Szabo, MD, PhD; Katherine H. Taber, PhD; Larry A. Tupler, PhD; Elizabeth E. Van Voorhees, PhD; H. Ryan Wagner, PhD; and Richard D. Weiner, MD, PhD, of the Durham VA Medical Center, Durham, NC; Scott D. McDonald, PhD, and Treven Pickett, PsyD, of the Hunter Holmes McGuire Department of Veterans Affairs Medical Center, Richmond, VA; Robin A. Hurley, MD; Jared Rowland, PhD; and Ruth E. Yoash-Gantz, PsyD, of the W.G. Hefner VA Medical Center, Salisbury, NC; Marinell Miller-Mumford, PhD, and Kathleen P. Decker, PhD, of the Hampton VA Medical Center, Hampton, VA; and Gregory McCarthy, PhD, Yale University, New Haven, CT.

Corresponding Author: Jaime M. Hughes, $\mathrm{PhD}$, MPH, MSW; Center for Health Services Research in Primary Care Durham VA Medical Center, 508 Fulton St (152), Durham, NC 27705, USA (e-mail: jane. hughes@va.gov).

Funding Center of Innovation for Health Services Research Primary Care (CIN 13-410); Office of Academic Affiliations, VA Health Services Research \& Development (Hughes; TPH 21-000); UNC Program on Integrative Medicine (Hughes; NIH/NCCIH T32AT003378); VA Career Development Program (Ulmer; CDA 09-218); VA Health Services Research \& Development (Gierisch; IIR 11-300).

\section{Compliance with Ethical Standards}

The views expressed in this manuscript are those of the authors and do not necessarily represent the views of the funding agencies or the federal government.

Conflict of Interest: The authors declare that they have no conflict of interest. 


\section{REFERENCES}

1. Seelig AD, Jacobson IG, Smith B, et al. Sleep patterns before, during, and after deployment to Iraq and Afghanistan. Sleep. 2011;33(12):161522.

2. Peterson AL, Goodie JL, Satterfield WA, Brim WL. Sleep disturbance during military deployment. Mil Med. 2008;173(230):235.

3. McLay RN, Klam WP, Volkert SL. Insomnia is the most commonly reported symptom and predicts other symptoms of post-traumatic stress disorder in U.S. service members returning from military deployments. Mil Med. 2010;175(10):759-62.

4. Plumb TR, Peachey JT, Zelman DC. Sleep disturbance is common among service members and Veterans of Operations Enduring Freedom and Iraqi Freedom. Psychol Serv. 2014;11(2):209-19.

5. Pilcher JJ, Huffcutt AJ. Effects of sleep deprivation on performance: A meta-analysis. Sleep. 1996;19(4):318-26. https://doi-org.proxy.lib.duke. edu/10.1093/sleep/19.4.318.

6. Katz DA, McHorney CA. The relationship between insomnia and healthrelated quality of life in patients with chronic illness. J Fam Pract. 2002;51(3):229-35.

7. Hunter G, Yoon J, Blonigen DM., Asch SM., Zulman DM. Health care utilization patterns among high-cost VA patients with mental health conditions. Psychiatr Serv. 2015;66:952-8.

8. Breslau N, Roth T, Rosenthal L, Andreski PM. Sleep disturbance and psychiatric disorders: A longitudinal study of young adults. Biol Psychiatry. 1996;39(6):411-8.

9. Ford D, Kamerow D. Epidemiologic study of sleep disturbances and psychiatric disorders: An opportunity for prevention? JAMA. 1989;262(11):1479-84.

10. Gehrman P, Seelig AD, Jacobson IG, et al. Predeployment sleep duration and insomnia symptoms as risk factors for new-onset mental health disorders following military deployment. Sleep. 2013;36(7):100918.

11. Wright KM, Britt TW, Bliese PD, Adler AB, Picchioni D, Moore D. Insomnia as predictor versus outcome of PTSD and depression among Iraq combat veterans. J Clin Psychol. 2011;67(12):1240-58.

12. Pigeon WR, Pinquart M, Connor K. Meta-analysis of sleep disturbance and suicidal thoughts and behaviors. J Clin Psychiatry. 2012;73(9):e1160-7.

13. Buysse DJ, Reynolds CF, Monk TH, Berman SR, Kupfer DJ. The Pittsburgh Sleep Quality Index: A new instrument for psychiatric practice and research. Psychiatry Res. 1989;23:193-213.

14. Bastien CH, Vallieres A, Morin CM. Validation of the Insomnia Severity Index as an outcome measure for insomnia research. Sleep Med. 2001;2:297-307.

15. Smith MT, Wegener ST. Measures of Sleep. Arthritis \& Rheumatism. 2003;49(5S):S184-S196

16. Aroll B, Goodyear-Smith F, Crengle SG J., et al. Validation of PHQ-2 and PHQ-9 to screen for major depression in the primary care population. Ann Fam Med. 2010;8:348-53.

17. Prins A, Ouimette $\mathbf{P}$, Kimerling $\mathbf{R}$, et al. The primary care PTSD screen (PC-PTSD): Development and operating characteristics. Primary Care Psychiatry. 2003;9(1):9-14.

18. Derogatis LR, Savitz KL. The SCL-90-R and the Brief Symptom Inventory (BSI) in Primary Care. In: Maruish M, ed. Handbook of Psychological Assessment in Primary Care Settings. Mahwah: Lawrence Erlbaum Associations; 2000:297-334.

19. Aroll B, Goodyear-Smith F, Crengle S, et al. Validation of PHQ-2 and PHQ-9 to screen for major depression in the primary care population. Ann Fam Med. 2010;8:348-53.
20. Blevins CA, Weathers FW, Davis MT, Witte TK, Domino JK. The Posttraumatic Stress Disorder Checklist for DSM-5 (PCL-5): Development and initial psychometric evaluation. J Trauma Stress. 2015;28:489-98.

21. MacGregor KL, Funderburk JS, Pigeon W, Maisto SA. Evaluation of the PHQ-9 Item 3 as a Screen for Sleep Disturbance in Primary Care. J Gen Intern Med. 2011;27(3):339-44.

22. Kulka RA, Sclenger WE, Fairbank JA, et al. Trauma and the Vietnam War generation: Report of the findings from the National Vietnam Veterans Readjustment Study. Vol 18. Philadelphia: Brunner/Mazel; 1990.

23. Derogatis LR, Savitz KL. The SCL-90-R, Brief Symptom Inventory, and Matching Clinical Rating Scales. In: Maruish M, ed. The use of psychological testing for treatment planning and outcomes assessment. 2nd ed. Mahwah: Lawrence Erlbaum Associations Publishers; 1999:679725.

24. Carpenter JS, Andrykowski MA. Psychometric evaluation of the Pittsburgh Sleep Quality Index. J Psychosom Res. 1988;45(1):5-13.

25. American Psychiatric Association. Desk Reference to the Diagnostic Criteria from DSM-5. Arlington, VA: American Psychiatric Association; 2013.

26. Davidson JRT, Book Sw, Colket JT, et al. Assessment of a new selfrating scale for post-traumatic stress disorder. Psychol Med. 1997;27:153-60.

27. Beck AT, Steer RA, Brown GK. Beck Depression Inventory Manual. San Antonio, TX: Psychological Corporation; 1996.

28. IBM Corp. Released 2012. IBM SPSS Statistics for Windows, Version 21.0 [computer program]. Armonk, NY: IBM Corp.

29. Hanley JA, McNeill BJ. A method of comparing the areas under receiver operating characteristic curves derived from the same cases. Radiology. 1983; 148:839-43.

30. Pepe MS. Receiver operating characteristic methodology. J Am Stat Assoc. 2000;95(449):308-11.

31. Swets JA. Measuring the accuracy of diagnostic systems. Science. 1988;240(4857): 1285-93.

32. Karlin BE, Trockel M, Taylor C, Gimeno J, Manber R. National dissemination of Cognitive Behavioral Therapy for Insomnia in Veterans: Therapist- and patient-level outcomes. J Consult Clin Psychol. 2013;81:912-7.

33. Kuhn E, Weiss BJ, Taylor KL., et al. CBT-I Coach: A Description and Clinician Perceptions of a Mobile App for Cognitive Behavioral Therapy for Insomnia. J Clin Sleep Med. 2016;12(4):597-606.

34. Manber R, Carney CE, Edinger JD. Dissemination of CBTI to the nonsleep specialist: Protocol development and training issues. J Clin Sleep Med. 2012;8:209-18.

35. Trockel M, Karlin BE, Taylor C, Manber R. Cognitive Behavioral Therapy for Insomnia with Veterans: Evaluation of effectiveness and correlates of treatment outcomes. Behav Res Ther. 2014;53:41-6.

36. Alexander M, Ray MA, Hebert JR, et al. The National Veteran Sleep Disorder Study: Descriptive epidemiology and secular trends, 20002010. Sleep. 2016;39(7):1399-1410.

37. Baglioni C, Battagliese G, Feige B, et al. Insomnia as a predictor of depression: A meta-analytic evaluation of longitudinal epidemiological studies. J Affect Disord. 2011;135:10-9.

38. Szklo-Coxe M, Young T, Peppard PE, Finn LA, Benca RM. Prospective associations of insomnia markers and symptoms with depression. Am J Epidemiol. 2010;171(6):709-20. 